\title{
Utility of a novel 3F coronary sinus catheter during simultaneous ablation of the left anterolateral accessory pathway and left ventricular summit premature ventricular contractions
}

\author{
Michał M. Farkowski, Piotr Gardziejczyk, Aleksander Maciąg, Mariusz Pytkowski \\ 2nd Department of Heart Arrhythmia, National Institute of Cardiology, Warsaw, Poland
}

Correspondence to: Michał M. Farkowski, MD, PhD, 2nd Department of Heart Arrhythmia, National Institute of Cardiology, ul. Alpejska 42, 04-628 Warszawa, Poland, phone: +48223434002 , email: mfarkowski@gmail.com Received: October 18, 2020. Revision accepted: November 7, 2020. Published online: November 18,2020 Kardiol Pol. 2021; 79 (1): 85-86 doi:10.33963/KP.15684 Copyright by the Author(s), 2021
In this clinical vignette, we present the case of a 64-year-old man with a history of palpitations due to premature ventricular contractions (PVCs) and the accessory pathway (AP) mapped using a novel 10-pole $3 \mathrm{~F}$ coronary sinus (CS) catheter and successfully ablated. The second procedure conducted due to previously undiagnosed atrioventricular nodal reentrant tachycardia confirmed the effectiveness of the first ablation.

A 64-year-old man with a history of 13 to 29 thousand PVCs/day (Supplementary material, Figure S1) on repeated Holter monitoring and intermittent preexcitation on surface electrocardiography was admitted for radiofrequency ablation. On admission, the patient was in a good condition, with normal left ventricular ejection fraction and an N-terminal fragment of the prohormone brain natriuretic peptide level of $206 \mathrm{pg} / \mathrm{ml}$.

The procedure was performed using a novel 10-pole 3F nonsteerable CS catheter and a 4-pole His/RV catheter (both by Hagmed, Rawa Mazowiecka, Poland). Arrhythmias were mapped and ablated using the Thermocool Smart Touch catheter (Biosense-Webster Inc., Diamond Bard, California, United States), CARTO 3 (Biosense-Webster Inc.), and Lab System PRO with a Template Matching module (Boston Scientific Corp., Marlborough, Massachusetts, United States). The 3F catheter was carefully introduced to the $C S$ via a long $6 \mathrm{~F}$ guiding catheter and advanced to the level of the great cardiac vein (GCV). At first, a left anterolateral AP responsible for antidromic atrioventricular reentrant tachycardia was identified and ablated (FIGURE 1A; Supplementary material, Figure S2). Then, PVC mapping revealed the earliest activation in the GCV at the distal end of the CS catheter. Aortic cusp and left ventricular outflow tract ablation did not abolish PVCs. Finally, a successful ablation was performed, targeting the area of the earliest activation on the $3 \mathrm{~F}$ catheter anatomically, directly from the area adjacent to the aortic-mitral continuity despite unremarkable local activation time and poor pace mapping (FIGURE 1B; Supplementary material, Figure S3) The ablation setup was as follows: $40 \mathrm{~W} / 30 \mathrm{ml}$ irrigation; application time, $40 \mathrm{~s}$. The final set of lesions is depicted in Supplementary material, Figure S4. The total study time was 2.25 hours, and total fluoroscopy time, $9.1 \mathrm{~min}$. The patient was discharged on the next day without complications. During a 9-month follow-up, the patient had fewer than 350 polymorphic PVCs/day, but he still suffered from narrow-complex tachycardias. During a redo procedure, there was no sign of the AP or PVC and typical atrioventricular nodal reentrant tachycardia was diagnosed and ablated. During the next 6 months of follow-up, the patient did not report any significant symptoms of arrhythmia.

Radiofrequency ablation is the treatment of choice in the case of symptomatic supraventricular tachycardias and PVCs. ${ }^{1,2}$ Although, according to the electrocardiographic pattern, the PVC was deemed to origin from the left ventricular inflow tract, the earliest activation in the GCV and the ablation technique used led us to believe that 

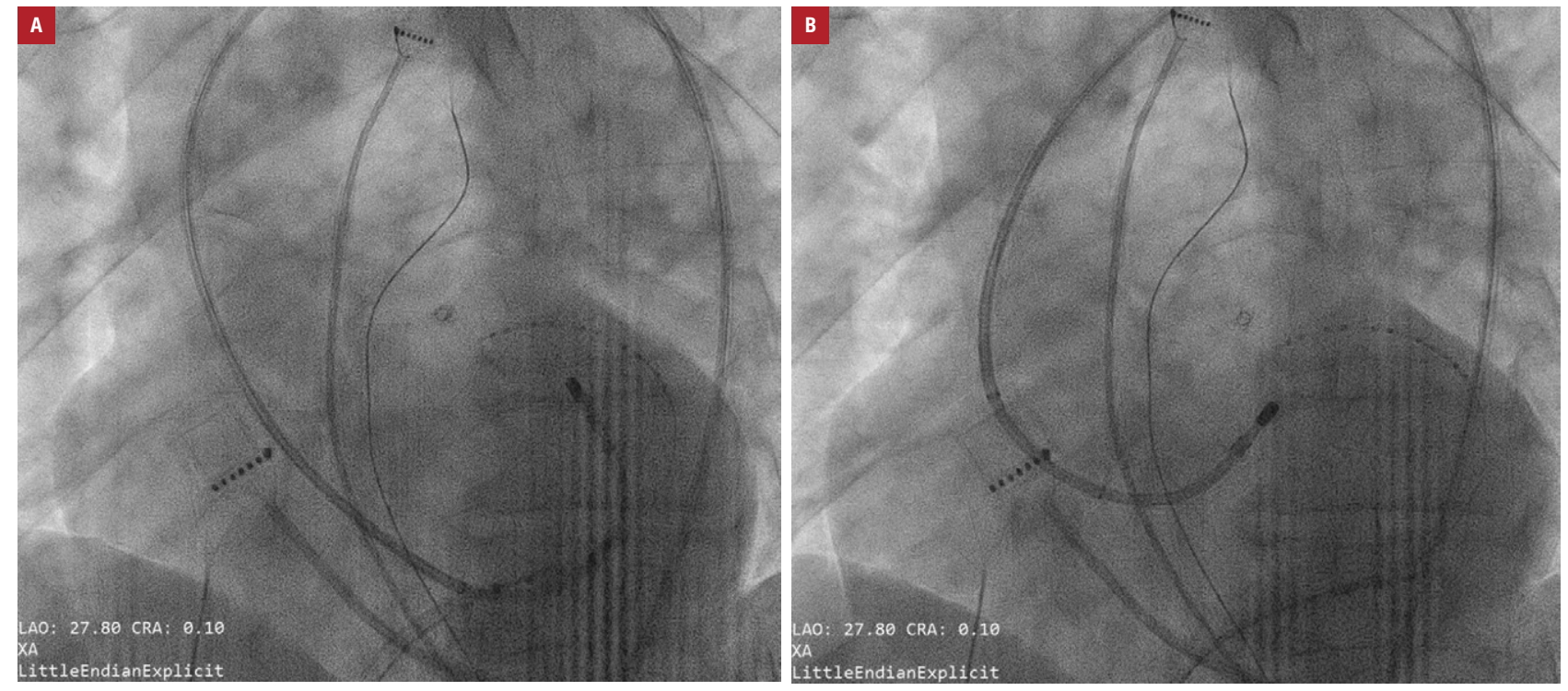

FIGURE 1 Position of the 3F coronary sinus catheter and the mapping catheter during the ablation of the accessory pathway (A) and premature ventricular contractions (B) visualized by fluoroscopy (approximately $30^{\circ}$ left anterior oblique view)

PVCs originated from the left ventricular summit. ${ }^{3}$ Contrary to the previous publication, ${ }^{3}$ we used a fine 10-pole 3F diagnostic catheter, another new catheter produced by Hagmed, ${ }^{4}$ instead of a guidewire, which facilitated meticulous mapping of both the AP and PVC. The second procedure indicated inability to access the GCV using a 10-pole 6F CS catheter in this patient while introduced via the standard femoral access.

\section{SUPPLEMENTARY MATERIAL}

Supplementary material is available at www.mp.pl/kardiologiapolska.

\section{ARTICLE INFORMATION}

CONFLICT OF INTEREST MMF, AM, and MP received speaker / proctoring honoraria from Abbott Medical Poland and Medtronic Poland.

OPEN ACCESS This is an Open Access article distributed under the terms of the Creative Commons Attribution-NonCommercial-NoDerivatives 4.0 International License (CC BY-NC-ND 4.0), allowing third parties to download articles and share them with others, provided the original work is properly cited, not changed in any way, distributed under the same license, and used for noncommercial purposes only. For commercial use, please contact the journal office at kardiologiapolska@ptkardio.pl.

HOW TO CITE Farkowski MM, Gardziejczyk P, Maciąg A, Pytkowski M. Utility of a novel $3 \mathrm{~F}$ coronary sinus catheter during simultaneous ablation of the left anterolateral accessory pathway and left ventricular summit premature ventricular contractions. Kardiol Pol. 2021; 79: 85-86. doi:10.33963/KP.15684

\section{REFERENCES}

1 Al-Khatib SM, Stevenson WG, Ackerman MJ, et al. 2017 AHA/ACC/HRS guideline for management of patients with ventricular arrhythmias and the prevention of sudden cardiac death: a Report of the American College of Cardiology/American Heart Association Task Force on Clinical Practice Guidelines and the Heart Rhythm Society. Heart Rhythm. 2018; 15: e73-e189.

2 Brugada J, Katritsis DG, Arbelo E, et al. 2019 ESC Guidelines for the management of patients with supraventricular tachycardiaThe Task Force for the management of patients with supraventricular tachycardia of the European Society of Cardiology (ESC). Eur Heart J. 2020; 41: 655-720.

3 Santangeli P, Marchlinski FE, Zado ES, et al. Percutaneous epicardial ablation of ventricular arrhythmias arising from the left ventricular summit: outcomes and electrocardiogram correlates of success. Circ Arrhythm Electrophysiol. 2015; 8: 337-343.

4 Kaczmarek K, Cygankiewicz I, Strzelecki A, et al. New Polish prototypes of 4 and 8-mm-tip nonirrigated radiofrequency ablation catheters: an in vitro study. Kardiol Pol. 2020; 78: 1142-1147. 